\title{
Position Paper on Lipid Therapy in Patients with Diabetes Mellitus
}

\author{
A Joint Statement by the Commission on Lipometabolism and The Heart and \\ Diabetes Working Group of the German Diabetes Society (DDG), The Diabetology \\ and Metabolism Section of The German Society of Endocrinology (DGE), The Heart \\ and Diabetes Working Group of the German Cardiology Society (DGK) and The Joint \\ Heart - Hormones - Diabetes Working Group of the DGK, DGE and DDG
}

\section{Authors}

Klaus G. Parhofer ${ }^{1}$, Andreas L. Birkenfeld ${ }^{2,3}$, Wilhelm Krone' ${ }^{4}$, Michael Lehrke ${ }^{5}$, Nikolaus Marx ${ }^{5}$, Martin Merkel ${ }^{6}$, Katharina S. Schütt ${ }^{5}$, Andreas Zirlik ${ }^{7}$, Dirk Müller-Wieland ${ }^{5}$

\author{
Affiliations \\ 1 Medical Department IV-Grosshadern, University of \\ Munich, Munich, Germany \\ 2 Medical Clinic IV, University Hospital, Tübingen, Germany \\ 3 Institute for Diabetes Research and Metabolic Diseases \\ (IDM) of Helmholtz Zentrum München at the Tübingen \\ University, German Centre for Diabetes Research, \\ Germany \\ 4 Polyclinic for Endocrinology, Diabetology and Preventive \\ Medicine, University Hospital Cologne, Cologne, \\ Germany \\ 5 Medical Clinic I - Cardiology, Angiology and Internal \\ Intensive Care Medicine, University Hospital Aachen, \\ Aachen, Germany \\ 6 Endocrinologikum Hamburg, Hamburg, Germany \\ 7 Clinic for Cardiology and Angiology I, University Heart \\ Centre, Freiburg, Germany
}

\section{Bibliography}

DOI https://doi.org/10.1055/a-1018-9228

Exp Clin Endocrinol Diabetes 2019; 127 (Suppl 1): S97-S101

(c) J. A. Barth Verlag in Georg Thieme Verlag KG Stuttgart .

New York

ISSN 0947-7349

\section{Correspondence}

Prof. Dr. med. Klaus G. Parhofer

Medical Department IV-Grosshadern

University of Munich

Marchioninistraße 15

81377 Munich

Germany

Klaus.Parhofer@med.uni-muenchen.de

\section{Introduction}

Patients with diabetes mellitus generally have a significantly increased cardiovascular risk. For this reason, lipid therapy and a reduction in LDL cholesterol based on risk stratification are an integral part of diabetes therapy; the following position paper should therefore also be viewed as a topic-related supplement to the annually updated recommendation for the treatment of type 2 diabetes and should also be updated annually in future together with the DDG's practical recommendations.

The recently published guidelines and recommendations of the European Society of Cardiology (ESC), the European Atherosclerosis Society (EAS), the American Association of Clinical Endocrinologists (AACE), the American Diabetes Association (ADA) and the American National Lipid Society (NLA) [1-5] form the basis for the information contained below.

This position paper is therefore to be understood as a short, current, clinically-oriented recommendation for action in patients with diabetes; for in-depth explanations on lipid metabolism and the use of lipid disorders, please refer to the literature provided.

\section{Stratification of Cardiovascular Risk}

Patients with diabetes mellitus usually have a significantly increased cardiovascular risk [6]. It is nonetheless recommended to break this risk down further. The same risk factors apply as for patients without diabetes ( $\triangleright$ Table 1). It should be noted that the presence of several risk factors has a cumulative effect on the overall risk [7]. The estimated overall risk is an essential determinant of whether and, if so, how intensively a lipid-lowering therapy should be carried out.

\section{Lipid Diagnostics}

The basis is made up of the determination of total cholesterol, LDLcholesterol, HDL-cholesterol and triglycerides as well as the calculation of the of the non-HDL cholesterol level. 
- Table 1 Further risk factors to be considered.

\begin{tabular}{|l|l|}
\hline Risk factor & Comment \\
\hline $\begin{array}{l}\text { Positive family history for premature } \\
\text { atherosclerosis events }\end{array}$ & $\begin{array}{l}\text { Atherosclerotic events before the age of } 55 \text { or } 65 \text { in men and women respectively; this age limit is currently } \\
\text { not evidence-based and should possibly be shifted upwards in the future in view of increasing life expectancy. }\end{array}$ \\
\hline Nicotine abuse & Number of "pack years" is relevant. \\
\hline Impaired renal function & The impairment of kidney function leads to an increase in the risk of atherosclerosis depending on the dosage. \\
\hline Hypertriglyceridemia & $\begin{array}{l}\text { Independent risk factor; probably also as an indicator for elevated non-HDL cholesterol with atherogenic } \\
\text { remnant particles }\end{array}$ \\
\hline HDL cholesterol reduction & Inverse risk factor in population studies; low HDL-C especially increases CV risk; frequent with high triglycerides \\
\hline Elevated blood pressure values & $>130 / 85 \mathrm{mmHg}$ or with antihypertensives \\
\hline
\end{tabular}

> Table 2 Classification of lipid metabolic disorders.

\begin{tabular}{|l|l|l|l|l|l|}
\hline Lipid disorder & Cholesterol & Triglyceride & LDL chol & HDL chol & non-HDL chol \\
\hline LDL hypercholesterolemia & $\uparrow$ & $\mathrm{n}$ & $\uparrow$ & $\mathrm{n}$ & $\uparrow$ \\
\hline Hypertriglyceridemia & $\uparrow$ & $\uparrow$ & $\mathrm{n}$ & $\downarrow$ & $\uparrow$ \\
\hline Combined hyperlipoproteinemia $\uparrow$ & $\uparrow$ & $\uparrow$ & $\mathrm{n}$ & $\downarrow$ & $\uparrow$ \\
\hline Isolated HDL cholesterol reduction $\uparrow$ & $\mathrm{n}$ & $\mathrm{n}$ & $\downarrow$ \\
\hline Lipoprotein(a) increase & Can occur in isolation or in combination with any lipid metabolism disorder. \\
\hline $\mathrm{n}=$ not changed.
\end{tabular}

- Table 3 Treatment targets for lipid metabolism disorders.

\begin{tabular}{|l|l|l|}
\hline Treatment & Clinical effect & Evidence \\
\hline $\begin{array}{l}\text { LDL cholesterol } \\
\text { reduction }\end{array}$ & $\begin{array}{l}\text { Reduction of atherosclerosis } \\
\text { events }\end{array}$ & Proven \\
\hline $\begin{array}{l}\text { Non-HDL cholesterol } \\
\text { reduction }\end{array}$ & $\begin{array}{l}\text { Reduction of atherosclerosis } \\
\text { events }\end{array}$ & Proven \\
\hline $\begin{array}{l}\text { Lowering of } \\
\text { lipoprotein(a) }\end{array}$ & $\begin{array}{l}\text { Reduction of atherosclerosis } \\
\text { events }\end{array}$ & Presumed \\
\hline Decrease triglycerides & Reduction of atherosclerosis events & Presumed \\
\hline $\begin{array}{l}\text { Reduction of highly } \\
\text { elevated triglycerides }\end{array}$ & $\begin{array}{l}\text { Reduction of the incidence of } \\
\text { acute pancreatitis }\end{array}$ & Proven \\
\hline
\end{tabular}

The lipoprotein(a) value should be determined once only. If there is no hypertriglyceridemia and the LDL cholesterol is determined directly, the determination can be carried out in a non-fasting state [8]. If the LDL cholesterol is calculated using the Friedewald formula, the patient should be fasting as the triglyceride level is included in the calculation. Genetic diagnosis is clinically justified in cases of high suspicion of familial hypercholesterolemia, if this has consequences for the indication and therapy strategy.

\section{Lipid Phenotype}

A distinction is made between hypercholesterolemia, hypertriglyceridemia and combined hyperlipidaemia. Clinically, secondary causes must be excluded or treated and important primary disorders, e. g. familial hypercholesterolemia, must be considered ( Table 2).

\section{Treatment of Lipid Metabolism Disorders in Patients with Diabetes Mellitus}

The primary goal of the treatment is to reduce the increased cardiovascular risk of patients with diabetes mellitus. The most important measure is the reduction of LDL cholesterol. Furthermore, the risk of acute pancreatitis can be reduced by lowering excessively elevated triglyceride levels. Normalization of elevated triglyceride levels can also improve blood glucose control ( $>$ Table 3 ).

\section{Therapy Strategies Aimed at Lowering LDL Cholesterol Levels}

In accordance with the recommendations of the European specialist societies, the reduction of LDL cholesterol levels is "target value-oriented", taking into account the cardiovascular risk [1]. A distinction is made between 3 categories that apply equally to patients with type 1 and type 2 diabetes mellitus ( $\triangleright$ Table 4 ).

Secondary target values are the concentrations of non-HDL cholesterol and apolipoprotein $\mathrm{B}$. This reflects the fact that probably all lipoproteins containing apolipoprotein B are atherogenic [9].

The non-HDL cholesterol value ( = total cholesterol minus HDL cholesterol) also approximately reflects this and includes VLDL cholesterol and remnant cholesterol in addition to LDL cholesterol. The non-HDL cholesterol target value is therefore relevant in patients with hypertriglyceridemia or mixed hyperlipidaemia (typically in patients with diabetes mellitus).

In normotriglyceridemia the VLDL/remnant cholesterol concentration is $<30 \mathrm{mg} / \mathrm{dl}$ (which corresponds to a triglyceride value of approximately $150 \mathrm{mg} / \mathrm{dl}$ ), which is why non-HDL cholesterol target values are each $30 \mathrm{mg} / \mathrm{dl}$ above the $\mathrm{LDL}$ cholesterol target value ( $\vee$ Table 4). For patients who meet the LDL cholesterol target but not 
> Table 4 Lipid target values in patients with diabetes mellitus.

\begin{tabular}{|c|c|c|c|c|}
\hline \multirow[b]{2}{*}{ Risk group } & \multirow[b]{2}{*}{ Definition } & \multirow{2}{*}{$\begin{array}{l}\text { Primary goal } \\
\text { LDL chol }\end{array}$} & \multicolumn{2}{|c|}{ Secondary targets } \\
\hline & & & Non-HDL chol & ApoB \\
\hline Very high risk & $\begin{array}{l}\text { Proven atherosclerosis and/or additional serious } \\
\text { risk factors }{ }^{1} \text { and/or end organ damage }{ }^{2} \text { or early } \\
\text { manifested type } 1 \text { diabetes with long diabetes } \\
\text { duration ( }>20 \text { years) }\end{array}$ & $\begin{array}{l}\geq 50 \% \text { reduction and target }<55 \mathrm{mg} / \mathrm{dl} \\
(1.4 \mathrm{mmol} / \mathrm{l}) \\
* \text { "ideal" target; clinically "good." } \\
\text { at }<70 \mathrm{mg} / \mathrm{dl}(1.8 \mathrm{mmol} / \mathrm{l})\end{array}$ & $\begin{array}{l}<85 \mathrm{mg} / \mathrm{dl} \\
(2.2 \mathrm{mmol} / \mathrm{l})\end{array}$ & $<65 \mathrm{mg} / \mathrm{dl}$ \\
\hline High risk & $\begin{array}{l}\text { Without proven atherosclerosis, without } \\
\text { terminal organ damage }{ }^{2} \text { with diabetes } \\
\text { duration }>10 \text { years or other risk factors }\end{array}$ & $\begin{array}{l}<70 \mathrm{mg} / \mathrm{dl}(1.8 \mathrm{mmol} / \mathrm{l}) \text { and } \geq 50 \% \\
\text { reduction of initial value }\end{array}$ & $<100 \mathrm{mg} / \mathrm{dl}$ & $<80 \mathrm{mg} / \mathrm{dl}$ \\
\hline $\begin{array}{l}\text { Moderately } \\
\text { increased risk }\end{array}$ & $\begin{array}{l}\text { Young patients with type } 1 \text { diabetes ( }<35 \text { years) } \\
\text { and type } 2 \text { diabetes ( }<50 \text { years) with diabetes } \\
\text { duration }<10 \text { years and no other risk factors }\end{array}$ & $<100 \mathrm{mg} / \mathrm{dl}(2.6 \mathrm{mmol} / \mathrm{l})$ & $\begin{array}{l}<130 \mathrm{mg} / \mathrm{dl} \\
(3.4 \mathrm{mmol} / \mathrm{l})\end{array}$ & undefined \\
\hline
\end{tabular}

For patients at the age of $\leq 30$ years and without indications for vascular damage or microalbuminuria, it seems reasonable to wait until the age of 30 years before beginning a statin therapy. ${ }^{1}$ Hypertension, nicotine abuse, severe dyslipoproteinemia ${ }^{2}$ E.g. microalbuminuria, retinopathy or neuropathy ${ }^{*}$ This addition to a clinical evaluation by the author group of this practical recommendation is based on the fact that the evidence for a further effective absolute risk reduction when comparing LDL-C values in treatment between $<70 \mathrm{mg} / \mathrm{dl}$ and $<55 \mathrm{mg} / \mathrm{dl}$ is still low and depends very much on the individual patient risk.

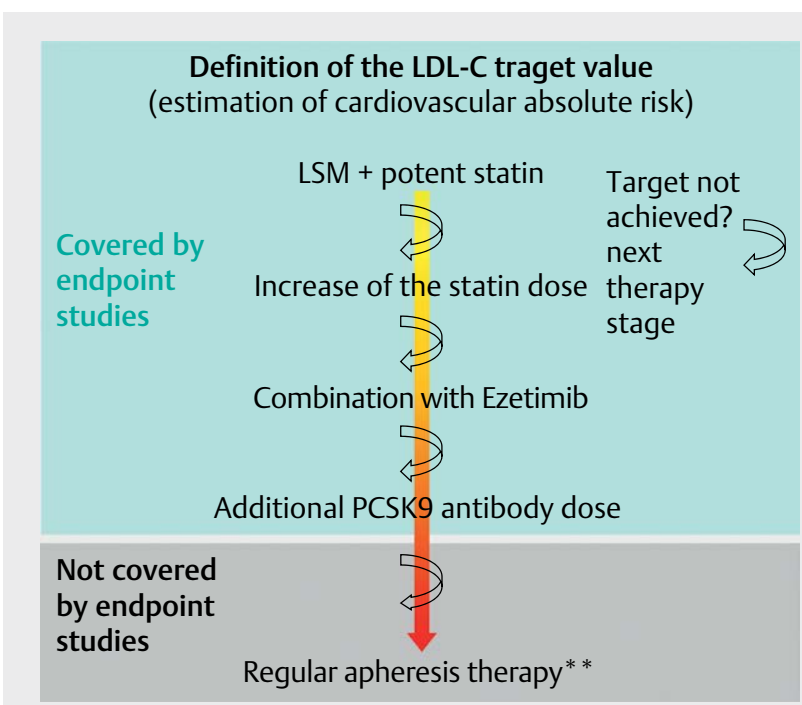

-Fig. 1 Therapy algorithm to achieve the LDL cholesterol target values. LSM: Lifestyle measures; ${ }^{*}$ according to the G-BA; ${ }^{*}$ as per individual benefit-risk assessment.

the non-HDL cholesterol target, the non-HDL cholesterol level can be achieved by either lowering the triglyceride level (reduction of VLDL/ remnant cholesterol) or further reducing the LDL cholesterol.

In addition, it should be mentioned that the American Diabetes Association (ADA) solely considers the age criteria (under/over 40 years) and presence of atherosclerosis (yes/no) [5]. All patients with atherosclerosis receive a high dose of statin (atorvastatin $40-80 \mathrm{mg} / \mathrm{d}$ or rosuvastatin $20-40 \mathrm{mg} / \mathrm{d}$ ) and can also be treated with ezetimibe and PCSK9 inhibitors if the LDL cholesterol level remains above $70 \mathrm{mg} / \mathrm{dl}$. For patients without atherosclerosis, those under 40 years of age do not generally receive a statin and those over 40 years of age receive a moderate statin dose (e. g. atorvastatin $20 \mathrm{mg} / \mathrm{d}$ or rosuvastatin $10 \mathrm{mg} / \mathrm{d}$ ).
Even if, at first glance, there are clear differences between the ADA and ESC recommendations, in both cases the fact is that the vast majority of patients with diabetes mellitus should be treated with statins.

In order to achieve the ESC target values mentioned above, a gradual therapy of statins, ezetimibe and PCSK9 antibodies can be used ( $\vee$ Fig. 1) [10]. After excluding or treating secondary causes of hyperlipidaemia, statins are used as the therapy of choice. If, despite a sufficient dose, this is not sufficient to achieve the individual target value, the next step is to combine it with ezetimibe and, as a third step, to combine it with PCSK9 inhibitors, especially in cases of clinical progression of cardiovascular disease.

According to the decision of the Federal Joint Committee/ Gemeinsamen Bundesausschuss (G-BA), PCSK9 inhibitors must be prescribed by a doctor of internal medicine with a specialization in cardiology, nephrology, endocrinology, angiology or by a special lipid outpatient clinic and can then be prescribed by the family doctor. As a last option, regular lipoprotein apheresis therapy is also possible, however, this should only be used when all other drug approaches have been exhausted. If the clinical indication is LDL apheresis, the G-BA decision is that the administration of a PCSK9 inhibitor is considered an alternative and economical option. In patients who are already on lipoprotein apheresis therapy primarily to lower LDL cholesterol, the administration of a PCSK9 antibody should reduce the apheresis frequency and even aim to terminate this therapeutic concept [11].

\section{Therapy Strategies for Elevated Triglycerides}

Lifestyle measures and blood glucose control are the primary strategies for hypertriglyceridemia and for the reduction of triglycerides in combined hyperlipidaemia [1]. The use of fibrates and high-dose fatty acids to further reduce significantly elevated triglyceride levels must be decided individually, as endpoint studies in combination with statins have shown no clear cardiovascular benefit ( $\triangleright$ Table 5). 
- Table 5 Therapy strategies for elevated triglycerides.

\begin{tabular}{|l|l|}
\hline Measure & Comment \\
\hline $\begin{array}{l}\text { Reaching LDL } \\
\text { cholesterol target value }\end{array}$ & Always; normally necessary to administer statins \\
\hline $\begin{array}{l}\text { Reaching non-HDL } \\
\text { target value }\end{array}$ & $\begin{array}{l}\text { If possible, either further LDL cholesterol reduction or reduction of VLDL/remnant cholesterol (and thus triglyceride } \\
\text { reduction). }\end{array}$ \\
\hline Lifestyle measures & $\begin{array}{l}\text { Always, as this can usually significantly improve hypertriglyceridemia. } \\
\text { Always, as this can usually significantly improve hypertriglyceridemia. }\end{array}$ \\
\hline Blood glucose control & $\begin{array}{l}\text { Individual assessment, possibly after achieving LDL cholesterol target values in cases of very high risk and persistent } \\
\text { hypertriglyceridemia; }{ }^{1} \text { cautious use, as no convincing endpoint studies in combination with statins have been conducted so } \\
\text { far; note: increased risk of myopathy in combination with statins. }\end{array}$ \\
\hline Fibrates & $\begin{array}{l}\text { Individual assessment, possibly after achieving LDL cholesterol target values in cases of very high risk and persistent } \\
\text { hypertriglyceridemia; cautious use, as no convincing endpoint studies in combination with statins have been conducted so far. }\end{array}$ \\
\hline \multicolumn{2}{|l|}{ As a dietary fat substitute for very high triglyceride values. } \\
\hline of acute pancreatitis.
\end{tabular}

\section{Therapy Strategies for Special Situations}

\section{Increased lipoprotein(a) levels}

Elevated Lp(a) values (or also low HDL cholesterol levels) cannot currently be specifically influenced by medication, therefore in these cases the remaining risk profile must be optimized and thus, e. g., an optimal adjustment of the LDL cholesterol should be sought. It is important to note that approx. $20 \%$ of the Lp(a) concentration is included in the LDL cholesterol determination, i. e. the LDL cholesterol value must be "corrected" for this. If lipoprotein(a) values are significantly elevated ( $>60 \mathrm{mg} / \mathrm{dl}$ ) and there is evidence of progressive atherosclerosis over one year despite optimal control of all other risk factors, regular lipoprotein apheresis therapy can be started to lower elevated lipoprotein(a) values.

\section{Statin intolerance}

Patients with diabetes mellitus and statin intolerance should be treated similarly to patients without diabetes and statin intolerance. At least 3 different statins should be used before a statin intolerance is diagnosed (exception: rhabdomyolysis induced by a statin - then a second statin should only be used very cautiously). In many patients, it is possible to use a low statin dose in combination with ezetimibe to significantly reduce LDL cholesterol levels. PCSK9 inhibitors are well-tolerated by a high number of patients with statin intolerance and can be used in patients with very high risk and significant distance to the target value. Data from Germany show that PCSK9 inhibitors are used in 70-80 \% of patients with statin intolerance. Quelle einfügen: Drugs Real World Outcomes. 2019Sep; 6(3):115-123. doi: 10.1007/s40801-019-0158-0. PEARL: A Non-interventional Study of Real-World Alirocumab Use in German Clinical Practice. Parhofer KG, von Stritzky B, Pietschmann N, Dorn C, Paar WD.

\section{Severe hypertriglyceridemia}

Triglyceride values above $1000 \mathrm{mg} / \mathrm{dl}$ significantly increase the risk of acute pancreatitis [12]. By consistently implementing lifestyle measures (alcohol abstinence, largely abstaining from refined carbohydrates) and a strict blood glucose control it is usually possible to lower the values significantly. In order to minimize the risk of pancreatitis in severe hypertriglyceridemia, fibrates and/or high doses of omega-3 fatty acids can be used to significantly reduce triglyceride levels. If acute pancreatitis occurs at triglyceride concentrations above $1000 \mathrm{mg} / \mathrm{dl}$, plasmapheresis is a treatment option to rapidly reduce the triglyceride concentration. Further treatment options include the administration of heparin and/or insulin (activation of lipoprotein lipase) and fasting. It is particularly worth trying a replacement of dietary fats with MCT fatty acids in cases of very high triglyceride values.

\section{Conclusion}

Cardiovascular events are a major cause of premature mortality and multimorbidity in people with diabetes. Risk stratified patientrelated $L D L$ cholesterol reduction is an evidence-based integral part of diabetes therapy and can improve the clinical prognosis of our patients. In the case of severe hypertriglyceridemia with values above $1000 \mathrm{mg} / \mathrm{dl}$, the following measures reduce triglyceride concentrations and therefore significantly reduce the risk of pancreatitis: lifestyle measures (alcohol abstinence, largely abstaining from refined carbohydrates), good blood glucose control, possible administration of fibrates and/or omega-3 fatty acids.

\section{Company Representatives}

K.G. Parhofer and D. Müller-Wieland represent the DDG.

A.L. Birkenfeld represents the AG Diabetes und Herz.

W. Krone and M. Merkel represent the DGE.

M. Lehrke, N. Marx, K.S. Schütt and A. Zirlik represent the AG Herz und Diabetes of the DGK.

Marx, W. Krone, D. Müller-Wieland represent the AG Herz- Hormone-Diabetes of the DGK-DGE-DDG. 


\section{Conflict of interest}

K.G.P. received lecture fees, fees for Advisory Board activities, fees for DMC activity and/or research support from the following companies: Aegerion, Akcea, Amarin, Amgen, Berlin- Chemie, Boehringer-Ingelheim, Ionis, Lilly, MSD, Regeneron, Sanofi. A.L.B. received lecture fees from Amgen, MSD and Sanofi. W.K. received lecture fees from Amgen, Bayer Vital, Boehringer Ingelheim, OmniaMed, Roche and Sanofi. N.M. has received support from Boehringer Ingelheim to lead clinical trials, acts as a consultant to Amgen, AstraZeneca, Bayer, BMS, Boehringer Ingelheim, MSD, NovoNordisk and Sanofi- Aventis and receives research funding from MSD and Boehringer Ingelheim. In addition, he has lectured for Amgen, AstraZeneca, Bayer, BMS, Boehringer Ingelheim, Lilly, MSD, NovoNordisk and Sanofi-Aventis. has received research funding for experimental and clinical studies from Boehringer Ingelheim and MSD; he has served as a consultant for Boehringer Ingelheim, SanofiAventis, MSD, AstraZeneca, Lilly, Novo- Nordisk, Amgen and Bayer and as a speaker for Boehringer Ingelheim, Sanofi-Aventis, MSD, AstraZeneca, Lilly, NovoNordisk and Bayer. has received fees and/or research funding from Amgen, Berlin- Chemie, MSD and Sanofi.

\section{German Diabetes Association: Clinical Practice Guidelines}

This is a translation of the DDG clinical practice guideline published in: Diabetologie 2019; 14 (Suppl 2): S226-S231, DOI https://doi. org/10.1055/a-0898-9895.

\section{References}

[1] Mach F, Baigent C, Catapano AL et al. 2019 ESC/EAS Guidelines for the management of dyslipidaemias: Lipid modification to reduce cardio- vascular risk. Eur Heart J 2019, doi:10.1093/eurheartj/ehz455

[2] Jacobson TA, Ito MK, Maki KC et al. National lipid association recommendations for patient-centered management of dyslipidemia: Part 1- full report. J Clin Lipidol 2015; 9: 129-169
[3] Jacobson TA, Maki KC, Orringer CE et al. National Lipid Association Recommendations for Patient-Centered Management of Dyslipidemia: Part 2. J Clin Lipidol 2015; 9: S1-S122 e1

[4] Jellinger PS, Handelsman Y, Rosenblit PD et al. American Association of Clinical Endocrinologists and American College of Endocrinology Guidelines for Management of Dyslipidemia and Prevention of Cardiovascular Disease - Executive Summary. Complete Appendix to Guidelines available at: http://journals.aace.com Endocr Pract 2017; 23: 479-497

[5] American Diabetes Association 9. Cardiovascular Disease and Risk Management: Standards of Medical Care in Diabetes-2018. Diabetes Care 2018; 41: (Suppl. 1) S86-S104

[6] Gregg EW, Li Y, Wang J et al. Changes in diabetes-related complications in the United States, 1990-2010. N Engl J Med 2014; 370: 1514-1523

[7] Yusuf S, Hawken S, Ounpuu S et al. Effect of potentially modifiable risk factors associated with myocardial infarction in 52 countries (the Interheart study): Case-control study. Lancet 2004; 364: 937-952

[8] Nordestgaard BG, Langsted A, Mora S et al. Fasting is not routinely required for determination of a lipid profile: Clinical and laboratory implications including flagging at desirable concentration cut-points-A joint consensus statement from the European Atherosclerosis Society and European Federation of Clinical Chemistry and Laboratory Medicine. Eur Heart J 2016; 37: 1944-1958

[9] Sniderman AD, De Graaf J, Couture P et al. Regulation of plasma LDL: The apoB paradigm. Clin Sci (Lond) 2010; 118: 333-339

[10] Parhofer KG. The Treatment of Disorders of Lipid Metabolism. Dtsch Arztebl Int 2016; 113: 261-268

[11] Moriarty PM, Parhofer KG, Babirak SP et al. Alirocumab in patients with heterozygous familial hypercholesterolaemia undergoing lipoprotein apheresis: The ODYSSEY ESCAPE trial. Eur Heart J 2016; 37: 35883595

[12] Ewald N, Kloer HU. Treatment options for severe hypertriglyceridemia (SHTG): The role of apheresis. Clin Res Cardiol Suppl 2012; 7: (Suppl. 1) 31-35 